\title{
Análise Físico-química do Leite Cru Refrigerado Proveniente das Propriedades Leiteiras da Região Sul Fluminense
}

\author{
Filipe Pereira de Paula \\ Universidade Severino Sombra, Centro de Ciências Exatas, \\ Tecnológicas e da Natureza, Curso de Química Industrial, \\ perera18@gmail.com \\ Carlos Eduardo Cardoso \\ Universidade Severino Sombra, Centro de Ciências Exatas, \\ Tecnológicas e da Natureza, Curso de Química Industrial, \\ cardoso221@yahoo.com.br \\ Maria Aparecida Carvalho Rangel \\ Universidade Severino Sombra, Centro de Ciências Exatas, \\ Tecnológicas e da Natureza, Curso de Química Industrial, \\ aparecida.rangel@uol.com.br
}

\begin{abstract}
Resumo: Este trabalho visou avaliar as características fisico-químicas do leite cru refrigerado entregue a Cooperativa Agro-Pecuária de Barra Mansa LTDA pelas propriedades leiteiras da região Sul Fluminense. Com base neste estudo, pode-se concluir que $100 \%$ das amostras analisadas estavam de acordo com os padrões estabelecidos pela legislação vigente.
\end{abstract}

Palavras-chave: Análise físico-química. Leite cru refrigerado. Qualidade de alimentos.

\section{Physical Chemistry Analysis of Milk Refrigerated Row Proceeding of Propriety Milkmaid Region of South Fluminense}

\begin{abstract}
This work aimed to evaluate the physico-chemical properties of milk delivered in refrigerated row Cooperative Agro-Livestock Barra Mansa LTDA the propriety of the milkmaid South Fluminense region. Based on this study, we can conclude that 100\% of the samples were in accordance with standards established by law.
\end{abstract}

Keywords: Physico-chemistry. Analysis. Refrigerated milk row. Feed Quality. 


\section{Introdução}

Entende-se por leite vacum de boa qualidade, sem outra especificação, o produto oriundo da ordenha completa e ininterrupta, em condições de higiene, de vacas sadias, bem alimentadas e descansadas. Esse deve ser transportado em carros-tanque isotérmicos e, no momento do seu recebimento na indústria, deve apresentar temperatura igual ou inferior a $7{ }^{\circ} \mathrm{C}$ (Brasil 2002). O leite proveniente de outros animais deve denominar-se segundo a espécie de que proceda.

O leite possui uma composição média (Tabela 1) que pode variar em função do tipo de espécie, raça, alimentação, estação do ano, doenças e período de lactação do animal (Silva et al 1997).

Tabela 1. Composição centesimal média do leite de vaca.

\begin{tabular}{lc}
\hline CONSTITUINTE & TEOR \% $(\mathrm{m} / \mathrm{m})$ \\
\hline Água & 87,3 \\
Gordura & 3,9 \\
Proteínas & 3,25 \\
Lactose & 4,6 \\
Minerais & 0,65 \\
Sólidos Totais & 12,7 \\
Sólidos não gordurosos & 8,8 \\
\hline
\end{tabular}

As proteínas do leite são essenciais em nossa dieta. As proteínas absorvidas por nosso corpo são utilizadas na construção das proteínas do corpo humano. Um fato importante com relação à nutrição é que 8 (para adultos) e 9 (para crianças) dos 20 aminoácidos não podem ser sintetizados pelo organismo humano. Como eles são necessários para manter o metabolismo adequado, têm que ser fornecidos através da alimentação. Estes são chamados aminoácidos essenciais e todos eles estão presentes no leite (Tetra Pak 2004).

Os carboidratos são a principal fonte de energia de nossa dieta, sendo a lactose um carboidrato encontrado somente no leite. Este é formado pela união de duas unidades, a galactose e a glicose (Figura 1). Se o leite for aquecido a uma temperatura elevada e mantido nesta temperatura durante um certo tempo, ele se torna marrom e adquire um sabor caramelizado. Este processo é chamado de caramelização e é o resultado da reação química entre a lactose e as proteínas (reação de Maillard) (Tetra Pak 2004). 


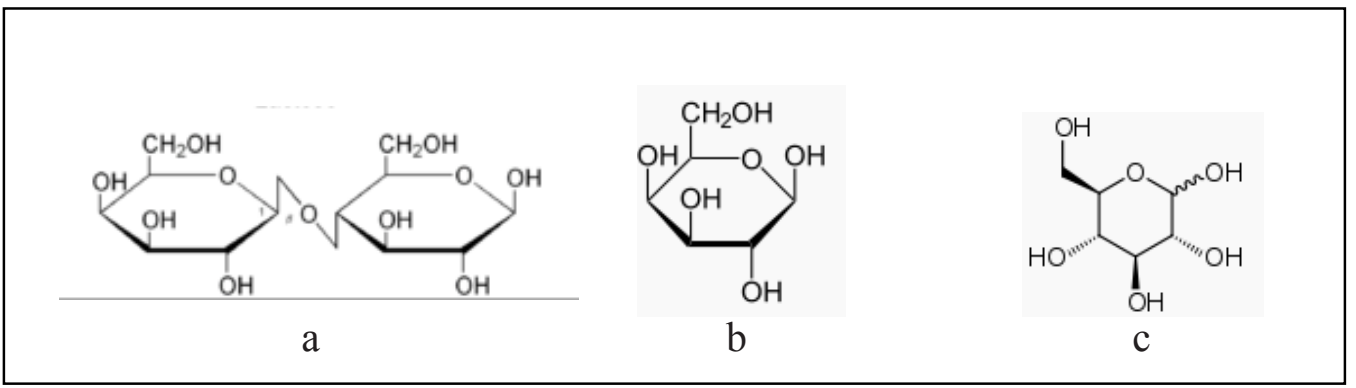

Figura 1. Representação esquemática da estrutura da lactose (a), da galactose (b) e da glicose (c).

Por outro lado, a gordura do leite ocorre em pequenos glóbulos contendo principalmente triacilgliceróis envolvidos por uma membrana lipoprotéica; o ácido palmítico e o ácido oléico são comumente encontrados (Silva et al 1997).

Atualmente, o consumidor tornou-se mais exigente e muitos são os requisitos que as indústrias precisam atender para comercializar os seus produtos nos mercados interno e externo. Nesse contexto, o Ministério da Agricultura, Pecuária e Abastecimento (MAPA) publicou no Diário Oficial da União de 18 de setembro de 2002, a Instrução Normativa $\mathrm{n}^{\mathrm{o}}$. 51 (IN 51), que regulamenta o padrão de identidade e qualidade do leite, incluindo manejo de ordenha, resfriamento na propriedade, transporte em grande quantidade, parâmetros físico-químicos, microbiológicos e contagem de células s omáticas, o que aumentou o nível de exigência nas propriedades e nas indústrias da área.

Neste sentido, as análises físico-químicas visam a avaliar o valor alimentar ou rendimento industrial e ainda detectar possíveis fraudes. Por esse motivo, a adoção conjunta de treinamentos, conscientização e capacitação dos produtores, desde o manejo de ordenha até a influência da qualidade da água na produção, torna-se essencial para alcançar a melhoria da qualidade do leite no país, visando, inclusive, ao seu destaque no mercado internacional (Mendonça, 2001) Adicionalmente, o controle de qualidade também se faz necessário, colocar a vírgula pois permite estabelecer um critério de pagamento ao produtor (Teixeira 1998).

A bonificação dos produtores pela qualidade da matéria-prima fornecida tem sido um tema atual e amplamente discutido. Assim, o nível de contaminação microbiana, os teores de gordura, de sólidos não gordurosos, a presença de inibidores entre outros parâmetros, podem tornar-se uma importante ferramenta para a melhoria da qualidade do leite no Brasil (Mendonça, 2001). Na região Sul Fluminense, muitos são os produtores que ainda recebem somente pelo litro de leite produzido. Entretanto, surgem algumas discussões se essa seria a melhor forma de pagamento, já que há grande divergência entre a qualidade da matéria-prima nas propriedades leiteiras.

Desta forma, o objetivo deste trabalho foi avaliar o leite cru refrigerado fornecido pelas propriedades leiteiras da região Sul Fluminense e entregues na Cooperativa Agro-Pecuária de Barra Mansa LTDA através da determinação de alguns parâmetros físico-químicos e sua concordância com a IN 51 do MAPA. 


\section{Materiais e Métodos}

Conforme preconiza a IN 51 e a IN 68 e, ainda, segundo sugerem Silva e colaboradores [1997], foram analisadas 20 amostras de leite cru refrigerado, recebidas em agosto de 2010 e provenientes de várias propriedades leiteiras da região Sul Fluminense. A amostragem foi realizada de acordo com as normas vigentes após a recepção dos carros-tanque. Em todos os casos, as amostras foram analisadas em triplicata.

A temperatura do leite foi verificada ainda nos carros-tanques com um termômetro de vidro (TEC LAB, Brasil). Uma amostra de leite foi retirada de cada boca é boca mesmo? do caminhão após o processo de agitação e levada para o laboratório imediatamente. Os frascos de coleta foram lavados e depois secos na estufa (FANEM modelo ORION 515, Brasil) com controlador do tipo termostato hidráulico. Em cada propriedade foi verificada a temperatura e realizado o teste do Alizarol.

Foram realizadas análises de acidez titulável, álcool, Alizarol, resíduos de antibióticos, depressão do ponto de congelamento (crioscopia), percentual de gordura, $\mathrm{pH}$; densidade a $15^{\circ} \mathrm{C}$; Extrato Seco Total (EST) com Disco de Ackermann e Extrato Seco Desengordurado (ESD) por meio de cálculos matemáticos, pesquisa de enzimas como a fosfatase e peroxidase; pesquisa de conservantes e reconstituintes como bicarbonatos e outros alcalinos (método ácido rosólico), amido, cloreto, sacarose, peróxido de hidrogênio e formol. Todas as análises foram realizadas segundo preconiza o Instituto Adolfo Lutz (2008).

Para a determinação da acidez titulável (em graus Dornic) foram utilizados um acidímitro Dornic, tubos de ensaio e suporte para os tubos de ensaio, pipetas graduadas de $10 \mathrm{~mL}$, solução Dornic (Hidróxido de Sódio 0,111 mol/L) e Fenolftaleína 1\% (m/v) alcoólica neutralizada.

Para o teste do álcool foram utilizados solução de álcool $78^{\circ}$ Gay-Lussac (GL), placas de Petri, pera de borracha, pipetas graduada de $10 \mathrm{~mL}$. Para o teste do Alizarol foram utilizados solução de alizarol $78^{\circ} \mathrm{GL}$ (Macalé), tubos de ensaio, pêra de borracha, pipetas graduadas de $10 \mathrm{~mL}$ e suporte para os tubos de ensaio.

Para a detecção de resíduos de antibióticos foram utilizados o "kit" teste da empresa DSM $\left(\right.$ Delvotest $^{\circledR}$ ), uma estufa DSM modelo Delvo Incubator e uma micropipeta. As ampolas do teste foram incubadas a $64^{\circ} \mathrm{C}$ por 3 horas.

Para determinação da Crioscopia foram utilizados um Crioscópio Eletrônico Microprocessado (modelo KP-7000 marca CAPI), tubos de ensaio específicos para o Crioscópico, estufa FANEM modelo ORION 515, suporte para os tubos, pipetas graduadas $10 \mathrm{~mL}$ e papel absorvente. As amostras foram previamente aquecidas em estufa.

Para determinação da gordura foram utilizados o equipamento da Instrumentos Para Laboratórios TR Ltda (ITR) modelo MK 2.5, pipetas graduadas de $10 \mathrm{~mL}$, bastão de vidro e béquer de $150 \mathrm{~mL}$. Todas as amostras foram agitadas durante 5 minutos antes das determinações.

Para determinação do $\mathrm{pH}$ foram utilizados phmetro com eletrodo de vidro combinado (Digimed, modelo DM-22), pipetas graduadas de $10 \mathrm{~mL}$, béquer de $150 \mathrm{~mL}$, água destilada, Piseta e papel absorvente. 
Para determinar a densidade a $15^{\circ} \mathrm{C}$ foram utilizados um termolactodensímetro (TEC LAB, Brasil) e proveta de $250 \mathrm{~mL}$. O Extrato Seco Total e o Extrato Seco Desengordurado foram determinados por cálculos matemáticos no Disco de Ackermann.

Para determinar a presença de fosfatase alcalina foi utilizado um "kit" fosfatase alcalina da empresa DIASYS, pera de borracha, pipetas graduadas de $10 \mathrm{~mL}$, tubos de ensaio e suporte para os tubos de ensaio. Para a presença de peroxidase foram utilizados solução de guaiacol $1 \%(\mathrm{v} / \mathrm{v})$ da TEC LAB (Brasil), solução de peróxido de hidrogênio a 10 volumes (CAP LAB, Brasil), pera de borracha, pipetas graduadas de $10 \mathrm{~mL}$, tubos de ensaio e suporte para os tubos de ensaio.

$\mathrm{Na}$ investigação da presença de bicarbonatos e outros alcalinos (método ácido rosólico) foram utilizados uma solução de ácido rosólico 1\% (CAP LAB, Brasil), álcool etílico neutralizado P.A. (CAP LAB, Brasil), tubos de ensaio, pera de borracha, pipetas graduadas de $10 \mathrm{~mL}$ e suporte para os tubos de ensaio.

Para verificar a presença de amido foram utilizados uma solução de lugol (CAP LAB, Brasil), tubos de ensaio, pera de borracha, pipetas graduadas de $10 \mathrm{~mL}$, suporte para os tubos de ensaio, garra de madeira e bico de Bunsen.

$\mathrm{Na}$ análise da presença de cloreto foram utilizados uma solução de cromato de Potássio $5 \%(\mathrm{~m} / \mathrm{v})$ uma solução de nitrato de prata a $10 \%(\mathrm{~m} / \mathrm{v})$, ambos da CAP LAB (Brasil), tubos de ensaio, pera de borracha, pipetas graduadas de $10 \mathrm{~mL}$ e suporte para os tubos de ensaio.

Para determinar a presença de sacarose foram utilizados ácido clorídrico P.A. (Synth), tubos de ensaio, pipetas graduadas de $10 \mathrm{~mL}$, pera de borracha, suporte para os de ensaio e Banho-Maria da ITR modelo $80 \mathrm{D}$ a uma temperatura de $60^{\circ} \mathrm{C}$.

Para determinar a presença de peróxido de hidrogênio foram utilizados solução guaiacol $1 \%(\mathrm{v} / \mathrm{v})$ da TEC LAB (Brasil), tubos de ensaio, pipetas graduadas de $10 \mathrm{~mL}$, pêra de borracha e suporte para os tubos de ensaio.

Para determinar a presença de formol foram utilizados ácido clorídrico P.A. (Synth), Cloreto Férrico 2,5\% (m/v) da CAP LAB, tubos de ensaio, garra de madeira, bico de Bunsen, pipetas graduadas de $10 \mathrm{~mL}$, pera de borracha e suporte para os tubos de ensaio.

\section{Resultados e Discussão}

De acordo com a IN 51 os parâmetros físico-químicos devem estar de acordo com os padrões de qualidade descritos na Tabela 2. Os métodos de análises recomendados são os indicados na mesma tabela e estão de acordo com o preconizado pelo Instituto Adolfo Lutz [2008] e por Brasil [2006]. Estas metodologias são as de referência, podendo ser utilizados outros métodos de controle operacional, desde que conhecidos os seus desvios e correlações em relação aos respectivos métodos de referência (Brasil 2002; Brasil, 2006). 
Análise Físico-química do Leite Cru Refrigerado Proveniente das Propriedades Leiteiras da Região Sul Fluminense

Filipe Pereira de Paula - Carlos Eduardo Cardoso - Maria Aparecida Carvalho Rangel

Tabela 2. Composição e requisitos físico-químicos do leite cru refrigerado

\begin{tabular}{lcc}
\hline \multicolumn{1}{c}{ Item de Composição } & Requisito & Método de Análise \\
\hline Gordura $(\mathrm{g} / 100 \mathrm{~g})$ & Min. 3,0 & IDF 1 C : 1987 \\
Acidez, em g de ácido láctico/100 $\mathrm{mL}$ & 0,14 a 0,18 & LANARA/MA, 1981 \\
Densidade relativa, $15 / 15^{\circ} \mathrm{C}, \mathrm{g} / \mathrm{mL}$ & 1,028 a 1,034 & LANARA/MA, 1981 \\
Índice Crioscópico máximo & $-0,530^{\circ} \mathrm{H}$ & IDF 108 A : 1969 \\
Sólidos Não-Gordurosos $(\mathrm{g} / 100 \mathrm{~g})$ & Min. 8,4 & IDF $21 \mathrm{~B}: 1987$ \\
Proteína Total $(\mathrm{g} / 100 \mathrm{~g})$ & Min. 2,9 & IDF 20 B : 1993 \\
Redutase (TRAM) & Min. 90 & CLA/DDA/MA \\
Estabilidade ao Alizarol $72 \%(\mathrm{v} / \mathrm{v})$ & Estável & CLA/DDA/MA \\
Estabilidade ao Alizarol $76 \%(\mathrm{v} / \mathrm{v})$ & Estável (1) & CLA/DDA/MA \\
\hline
\end{tabular}

Nota: Aplicável à matéria-prima recebida em estabelecimentos sob SIF após as 10:00 h da manhã do dia de sua obtenção.

As amostras (as amostras são denominadas compostas, pois cada caminhão passa por diferentes propriedades leiteiras) foram analisadas no laboratório da Cooperativa AgroPecuária de Barra Mansa LTDA obedecendo aos métodos analíticos oficiais ou utilizando métodos de controle operacional autorizados pelo MAPA e de acordo com o Regulamento Técnico de Identidade e Qualidade do Leite Cru Refrigerado da IN 51 (Brasil 2002). Nas vinte amostras analisadas (todas em triplicata), não foi verificada a presença de conservantes ou substâncias químicas geralmente utilizadas na fraude do leite. Quanto às características físico-químicas das amostras analisadas, os resultados são mostrados na Tabela 3 e 4.

Tabela 3. Resultado das análises do leite cru refrigerado dos carros-tanque.

\begin{tabular}{lccccccc}
\hline \multicolumn{1}{c}{ Amostra } & $\mathbf{1}$ & $\mathbf{2}$ & $\mathbf{3}$ & $\mathbf{4}$ & $\mathbf{5}$ & $\mathbf{6}$ & $\mathbf{7}$ \\
\hline Temperatura $\left({ }^{\circ} \mathrm{C}\right)$ & 6 & 6,5 & 6,5 & 6,5 & 6 & 6 & 6 \\
Antibiótico & - & - & - & - & - & - & - \\
Acidez $\left({ }^{\circ} \mathrm{D}\right)$ & 16 & 15 & 15 & 15 & 15 & 15 & 15 \\
$\mathrm{~N}^{\circ}$ Álcool $\left(78^{\circ} \mathrm{GL}\right)$ & Estável & Estável & Estável & Estável & Estável & Estável & Estável \\
Crioscopia $\left({ }^{\circ} \mathrm{H}\right)$ & $-0,539$ & $-0,54$ & $-0,542$ & $-0,54$ & $-0,537$ & $-0,538$ & $-0,536$ \\
Gordura \% $(\mathrm{m} / \mathrm{v})$ & 3,2 & 3,4 & 3,5 & 3,4 & 3,3 & 3,4 & 3,3 \\
pH & 6,69 & 6,69 & 6,67 & 6,68 & 6,72 & 6,71 & 6,74 \\
Densidade $15^{\circ} \mathrm{C}$ & 1,0308 & 1,031 & 1,031 & 1,031 & 1,0312 & 1,031 & 1,0308 \\
E.S.T. \% $(\mathrm{m} / \mathrm{v})$ & 11,79 & 12,08 & 12,21 & 12,08 & 12,02 & 12,08 & 11,92 \\
E.S.D. \% $(\mathrm{m} / \mathrm{v})$ & 8,59 & 8,68 & 8,71 & 8,68 & 8,72 & 8,68 & 8,62 \\
Fosfatase & + & + & + & + & + & + & + \\
Peroxidase & + & + & + & + & + & + & + \\
Amido & - & - & - & - & - & - & - \\
Alcalino & - & - & - & - & - & - & - \\
Cloreto & - & - & - & - & - & - & - \\
Sacarose & - & - & - & - & - & - & - \\
P. Hidrogênio & - & - & - & - & - & - & - \\
Formol & - & - & - & - & - & - & - \\
Alizarol & - & - & - & - & - & - & - \\
\hline
\end{tabular}


Análise Físico-química do Leite Cru Refrigerado Proveniente das Propriedades Leiteiras da Região Sul Fluminense

Filipe Pereira de Paula - Carlos Eduardo Cardoso - Maria Aparecida Carvalho Rangel

\begin{tabular}{lccccccc}
\hline \multicolumn{1}{c}{ Amostra } & $\mathbf{8}$ & $\mathbf{9}$ & $\mathbf{1 0}$ & $\mathbf{1 1}$ & $\mathbf{1 2}$ & $\mathbf{1 3}$ & $\mathbf{1 4}$ \\
\hline Temperatura $\left({ }^{\circ} \mathrm{C}\right)$ & 7 & 6 & 7 & 6 & 7 & 7 & 6 \\
Antibiótico & - & - & - & - & - & - & - \\
Acidez $\left({ }^{\circ} \mathrm{D}\right)$ & 15 & 15 & 15 & 15 & 15 & 15 & 15 \\
$\mathrm{~N}^{\circ}$ Álcool $\left(78^{\circ} \mathrm{GL}\right)$ & Estável & Estável & Estável & Estável & Estável & Estável & Estável \\
Crioscopia $\left({ }^{\circ} \mathrm{H}\right)$ & $-0,537$ & $-0,545$ & $-0,536$ & $-0,547$ & $-0,534$ & $-0,534$ & $-0,546$ \\
Gordura $\%(\mathrm{~m} / \mathrm{v})$ & 3,3 & 3,5 & 3,5 & 3,2 & 3,2 & 3,2 & 3,4 \\
pH & 6,72 & 6,7 & 6,77 & 6,76 & 6,73 & 6,7 & 6,7 \\
Densidade $15^{\circ} \mathrm{C}$ & 1,031 & 1,031 & 1,0308 & 1,0312 & 1,031 & 1,0309 & 1,031 \\
E.S.T. \% $(\mathrm{m} / \mathrm{v})$ & 11,97 & 12,21 & 12,16 & 11,9 & 11,85 & 11,83 & 12,08 \\
E.S.D. \% $(\mathrm{m} / \mathrm{v})$ & 8,67 & 8,71 & 8,66 & 8,7 & 8,65 & 8,63 & 8,68 \\
Fosfatase & + & + & + & + & + & + & + \\
Peroxidase & + & + & + & + & + & + & + \\
Amido & - & - & - & - & - & - & - \\
Alcalino & - & - & - & - & - & - & - \\
Cloreto & - & - & - & - & - & - & - \\
Sacarose & - & - & - & - & - & - & - \\
P. Hidrogênio & - & - & - & - & - & - & - \\
Formol & - & - & - & - & - & - & - \\
Alizarol & - & - & - & - & - & - & - \\
\hline
\end{tabular}

\begin{tabular}{|c|c|c|c|c|c|c|}
\hline Amostra & 15 & 16 & 17 & 18 & 19 & 20 \\
\hline Temperatura $\left({ }^{\circ} \mathrm{C}\right)$ & 6 & 6,5 & 6 & 6 & 6 & 6 \\
\hline Antibiótico & - & - & - & - & - & - \\
\hline Acidez ( $\left.{ }^{\circ} \mathrm{D}\right)$ & 15 & 15 & 16 & 15 & 15 & 15 \\
\hline $\mathrm{N}^{\circ}$ Álcool $\left(78^{\circ} \mathrm{GL}\right)$ & Estável & Estável & Estável & Estável & Estável & Estável \\
\hline Crioscopia $\left({ }^{\circ} \mathrm{H}\right)$ & $-0,537$ & $-0,538$ & $-0,54$ & $-0,54$ & $-0,537$ & $-0,535$ \\
\hline Gordura \% (m/v) & 3,5 & 3,5 & 3,6 & 3,4 & 3,2 & 3,5 \\
\hline $\mathrm{pH}$ & 6,68 & 6,68 & 6,65 & 6,68 & 6,71 & 6,71 \\
\hline Densidade $15^{\circ} \mathrm{C}$ & 1,0308 & 1,0309 & 1,031 & 1,0311 & 1,0312 & 1,0308 \\
\hline E.S.T. \% (m/v) & 12,16 & 12,18 & 12,33 & 12,11 & 11,9 & 12,16 \\
\hline E.S.D. \% (m/v) & 8,66 & 8,68 & 8,73 & 8,71 & 8,7 & 8,66 \\
\hline Fosfatase & + & + & + & + & + & + \\
\hline Peroxidase & + & + & + & + & + & + \\
\hline Amido & - & - & - & - & - & - \\
\hline Alcalino & - & - & - & - & - & - \\
\hline Cloreto & - & - & - & - & - & - \\
\hline Sacarose & - & - & - & - & - & - \\
\hline P. Hidrogênio & - & - & - & - & - & - \\
\hline Formol & - & - & - & - & - & - \\
\hline Alizarol & - & - & - & - & - & - \\
\hline
\end{tabular}

Nota: Foram coletados amostras em triplicatas do caminhão. 
Análise Físico-química do Leite Cru Refrigerado Proveniente das Propriedades Leiteiras da Região Sul Fluminense

Filipe Pereira de Paula - Carlos Eduardo Cardoso - Maria Aparecida Carvalho Rangel

Tabela 4. Resultado das análises do leite cru refrigerado dos carros-tanque.

\begin{tabular}{|c|c|c|c|c|c|}
\hline AMOSTRA & Média & Mínimo & Máximo & Amplitude & $\begin{array}{l}\text { Desvio } \\
\text { Padrão }\end{array}$ \\
\hline Temperatura $\left({ }^{\circ} \mathrm{C}\right)$ & 6,3 & 6,0 & 7,0 & 1,0 & 0,4104 \\
\hline \multicolumn{6}{|l|}{ Antibiótico } \\
\hline Acidez $\left({ }^{\circ} \mathrm{D}\right)$ & 15,1 & 15,0 & 16,0 & 1,0 & 0,3078 \\
\hline \multicolumn{6}{|l|}{$\mathrm{N}^{\circ}$ Álcool $\left(78^{\circ} \mathrm{GL}\right)$} \\
\hline Crioscopia $\left({ }^{\circ} \mathrm{H}\right)$ & $-0,539$ & $-0,547$ & $-0,534$ & 0,013 & 0,0037 \\
\hline Gordura \% (m/v) & 3,375 & 3,20 & 3,60 & 0,40 & 0,1293 \\
\hline $\mathrm{pH}$ & 6,705 & 6,65 & 6,77 & 0,12 & 0,0298 \\
\hline Densidade $15^{\circ} \mathrm{C}$ & 1,0310 & 1,0308 & 1,0312 & 0,0004 & 0,0001 \\
\hline E.S.T. \% $(\mathrm{m} / \mathrm{v})$ & 12,051 & 11,79 & 12,33 & 0,54 & 0,1478 \\
\hline E.S.D. \% $(\mathrm{m} / \mathrm{v})$ & 8,676 & 8,59 & 8,73 & 0,14 & 0,0353 \\
\hline \multicolumn{6}{|l|}{ Fosfatase } \\
\hline \multicolumn{6}{|l|}{ Peroxidase } \\
\hline \multicolumn{6}{|l|}{ Amido } \\
\hline \multicolumn{6}{|l|}{ Alcalino } \\
\hline \multicolumn{6}{|l|}{ Cloreto } \\
\hline \multicolumn{6}{|l|}{ Sacarose } \\
\hline \multicolumn{6}{|l|}{ P. Hidrogênio } \\
\hline \multicolumn{6}{|l|}{ Formol } \\
\hline Alizarol & & & & & \\
\hline
\end{tabular}

As vinte amostras analisadas correspondem a vinte caminhões de diferentes rotas da região Sul Fluminense. Por motivos corporativos e para sigilo dos próprios proprietários leiteiros não foi possível citar as rotas de cada caminhão.

A temperatura apresentou uma variação entre 6 a $7{ }^{\circ} \mathrm{C}$, o que é considerado adequado. No caso da determinação da acidez, cada $0,1 \mathrm{~mL}$ gasto da solução Dornic na titulação, inferiu $1^{\circ} \mathrm{D}$ e, cada $1{ }^{\circ} \mathrm{D}$ correspondeu a $0,01 \%$ de acidez expressa como ácido lático. Os resultados mostraram valores entre 15 e $16^{\circ} \mathrm{D}$.

A presença de resíduos de antibióticos no leite resulta da aplicação de diferentes substâncias antimicrobianas no efetivo leiteiro, para prevenção ou tratamento de doenças, com destaque para as infecções da glândula mamária e as doenças do trato reprodutivo. Diferentes tipos de antibióticos e suas combinações são utilizadas para estes fins. O leite contaminado por resíduos de antibióticos é considerado adulterado e impróprio para consumo. No caso dos testes realizados, $100 \%$ foram negativos, indicando não haver 
riscos para a saúde pública, riscos tecnológicos para a indústria de lacticínios e riscos comerciais.

A prova do álcool é o primeiro teste de qualidade feito na fazenda antes da coleta do leite pelo motorista. O teste é rápido e simples para identificação de leite ácido, estabelecido pelo Ministério da Agricultura Pecuária e Abastecimento (MAPA), que determina as normas de qualidade do leite através da instrução normativa 51 (IN51), publicada em 2002.

O álcool atua como desidratante do leite e simula a estabilidade do leite ao aquecimento. Quanto menor a concentração do álcool usado no teste menor a estabilidade do leite. A recomendação da IN 51 é que o leite tenha estabilidade ao álcool no mínimo de $72 \%$. O leite ácido advém da alta contagem bacteriana (CBT), devido à falta de higiene no momento da ordenha, falhas no resfriamento do leite e/ou no transporte do leite. A lactose ou açúcar do leite é fermentado pelas bactérias presentes no leite produzindo o ácido lático que desestabiliza a proteína do leite formando coágulos na reação com álcool. Neste estudo, todas as amostras apresentaram $100 \%$ de estabilidade no teste do álcool.

A temperatura de congelamento do leite é mais baixa do que a da água devido ao efeito das substâncias dissolvidas no leite, principalmente a lactose e os sais minerais. $\mathrm{O}$ índice crioscópico ou crioscopia é a medida do ponto de congelamento do leite ou da depressão do ponto de congelamento do leite em relação ao da água. O ponto de congelamento máximo do leite aceito pela legislação brasileira é - $0,512{ }^{\circ} \mathrm{C}\left(0,530^{\circ} \mathrm{C}\right)$. Como essa é uma das características físicas mais constantes do leite, é usada para detectar adulteração deste com água. Quando se adiciona água ao leite, o ponto de congelamento aumenta em direção ao ponto de congelamento da água $\left(0^{\circ} \mathrm{C}\right)$. Os resultados da Tabela 2 mostram $\left(-0,534\right.$ a $\left.-0,547^{\circ} \mathrm{H}\right)$, entretanto, uma pequena variação neste sentido mas que, em um nível de confiança de $95 \%$, não apresenta diferença significativa em relação ao preconizado pela legislação.

Também um importante parâmetro para avaliar fraudes, o teor de gordura do leite deve ser, em média, igual a 3,5\%. Neste estudo, tal índice apresentou uma variação entre 3,2 e $3,6 \%(\mathrm{~m} / \mathrm{v})$.

A medição do $\mathrm{pH}$ foi similar ao teste do álcool, porém um indicador de $\mathrm{pH}$ (alizarina) permitiu estimar o $\mathrm{pH}$ da amostra, compensando o desequilíbrio salino e a acidez excessiva. $\mathrm{O} \mathrm{pH}$ do leite recém ordenhado de uma vaca pode variar entre 6,4 a 6,8, e também pode ser um indicador da qualidade sanitária e da estabilidade térmica do leite. Nos casos graves de mastite, o $\mathrm{pH}$ pode chegar a 7,5 e na presença de colostro, pode cair a 6,0 . Como as amostras apresentaram uma variação entre 6,65 a 6,77, todas as 20 amostras estavam dentro do recomendado.

A densidade do leite é uma relação entre sua massa e seu volume e é normalmente medida a $15{ }^{\circ} \mathrm{C}$ ou corrigida para essa temperatura. A densidade do leite é, em média, $1,032 \mathrm{~g} / \mathrm{mL}$, podendo variar entre 1,023 e 1,040 g/mL. A densidade da gordura do leite é aproximadamente 0,927 e a do leite desnatado, cerca de 1,035. Assim, um leite com 3,0\% de gordura deverá ter uma densidade em torno de 1,0295, enquanto um com 4,5\% deverá ter uma densidade de 1,0277. Através dela, colocar a vírgula é possível avaliar a relação entre os sólidos e o solvente no leite, utilizado juntamente com o teste de gordura para 
determinar o teor de sólidos do leite. A densidade abaixo do nível serve para identificar fraude no leite (água), problemas nutricionais ou ainda problemas na saúde do animal. Os resultados obtidos não indicaram a presença de água (fraude) nas amostras (densidade entre 1,0308 a 1,0312 g/mL). Adicionalmente, o EST apresentou variação entre 11,79 e $12,33 \%(\mathrm{~m} / \mathrm{v})$ e o ESD de 8,59 a 8,73.

Nos testes de fosfatase todas as amostras apresentaram resultados positivos. Como a fosfatase é uma enzima termo sensível, que está sempre presente no leite cru, a destruição da fosfatase pelo calor mantém relação direta com a temperatura e o tempo de aquecimento, já que, colocar a vírgula quando o leite é aquecido, colocar a vírgula observa-se que a fosfatase é totalmente destruída. Os resultados indicam, portanto, que as amostras não foram previamente pasteurizadas, isto é, não sofreram aquecimento.

Das enzimas presentes no leite a peroxidase é a mais termoresistente. Ela tem a propriedade de oxidar o peróxido de hidrogênio gerando oxigênio e água, que transforma o guaiacol de forma leuco para forma corada. A enzima transfere o íon hidrogênio do guaiacol para o peróxido e o guaiacol muda sua coloração para salmão. O teste de peróxido no leite deve ser positivo; colocar o ponto e vírgula quando negativo indica que o leite foi super aquecido ou fervido. Neste estudo, $100 \%$ dos testes de peroxidase foram positivos, corroborando as observações anteriores.

\section{Conclusões}

A determinação dos parâmetros físico-químicos exigidos pela IN 51 do MAPA permite concluir que todas as 20 amostras recebidas na Cooperativa Agro-Pecuária de Barra Mansa LTDA estão dentro dos padrões estabelecidos pela legislação vigente. Adicionalmente, pode-se concluir que as metodologias utilizadas neste trabalho podem ser aplicadas para identificar fraude no leite, problemas nutricionais ou ainda problemas na saúde do animal.

\section{Agradecimentos}

Os autores agradecem a Cooperativa Agro-Pecuária de Barra Mansa LTDA que gentilmente cederam a estrutura do laboratório para a realização deste trabalho. 


\section{Referências}

Brasil. Ministério da Agricultura, Pecuária e Abastecimento. Instrução Normativa ${ }^{\circ}$. 68, de 12 de dezembro de 2006. "Métodos Analíticos Oficiais físico-químicos, para controle de leite e produtos lácteos", endereço: http://extranet.agricultura.gov. br/ sislegis-consulta/consultarLegislacao.do?operacao=visualizar\&id=17472, Acesso em 23/06/09.

Brasil. Ministério da Agricultura, Pecuária e Abastecimento. Instrução Normativa $\mathrm{n}^{\circ}$. 51, de 18 de setembro de 2002. "Regulamentos Técnicos de Produção, Identidade e Qualidade do leite tipo A, do leite tipo B, do leite tipo C, do Leite Pasteurizado e do Leite Cru Refrigerado e Regulamento Técnico da Coleta de Leite Cru Refrigerado e seu Transporte a Granel", endereço: http://extranet.agricultura.gov.br/sislegis-consulta/ consultarLegislacao.do?operacao=visualizar\&id=8932, Acesso em 23/06/09.

Instituto Adolfo Lutz. Métodos físico-químicos para análise de alimentos. Coord. Odair Zenebon, Neus Sadocco Pascuet e Paulo Tiglea. São Paulo: Instituto Adolfo Lutz, 2008. p. 1020.

Mendonça, A.H. Qualidade físico-química de leite cru resfriado: comparação de diferentes procedimentos e locais de coleta. In: Congresso Nacional de Laticínios, 18, 2001, Juiz de Fora. Anais do Congresso Nacional de Laticínios. Juiz de Fora: Templo. 2001. p.276-282.

Silva, P.H.F., Pereira, D.B.C., Oliveira, L.L., Costa Júnior, L.C.G., Físico-Química do Leite e Derivados: Métodos Analíticos. Oficina de Impressão Gráfica, Juiz de Fora, 1997.

Teixeira, S.R. Pagamento pela Qualidade. In: Brito, J.R.F.; Dias, J.C. A Qualidade do Leite. Embrapa/Tortuga,. p.51-58, 1998.

Tetra Pak Brasil. Curso Básico de UHT para Supervisores, Brasil, 2004. 